\title{
Arquivo na Arte Contemporânea
}

\author{
PRISCILA ARANTES ${ }^{1}$
}

Resumo

A partir de considerações a respeito da crise da história e da história da arte, Arquivo na Arte Contemporânea discute a forma com que o arquivo é trabalhado pelos artistas. Artistas que trabalham com material de arquivo, que criam arquivos

Palavras-chave: Arquivo, arte contemporânea, história da arte fictícios, que problematizam a questão do arquivamento e que desenvolvem projetos a partir de uma modalidade arquival, são algumas das propostas discutidas no presente ensaio. 


\title{
The archive in contemporary art
}

PRISCILA ARANTES

\begin{abstract}
From considerations regarding the crisis of history and art history, Archive in Contemporary Art discusses the way in which artists have been working with the archive. Artists who work with archival material, that create fictitious files, who question the issue of archiving and develop projects from an own archival mode, are some of the proposals discussed in this article.
\end{abstract}




\title{
Archivo en el Arte Contemporáneo
}

\author{
PRISCILA ARANTES ${ }^{1}$
}

\section{Resumen}

A partir de consideraciones a respeto de la crisis de la historia y de la historia del arte, Archivo en el Arte Contemporáneo discute la forma con que el archivo es trabajado por los artistas. Artistas que trabajan con material de archivo, que crean archivos ficticios, que problematizan la cuestión del

Palabras clave: Archivo, arte contemporáneo, historia del arte archivamiento y que desarrollan proyectos a partir de una modalidad archival, son algunas de las propuestas discutidas en el presente ensayo. 
A ideia de uma era de epílogos tem sido um dos grandes temas do nosso século. É dentro dessa perspectiva que encontramos pensadores como Walter Benjamin que combatem o conceito iluminista de história propondo alternativas para outra história narrada na contramão da história dita oficial.

Em suas teses Sobre o Conceito de História, Benjamin aponta para a necessidade de se escrever uma história a contrapelo, uma história que contrariamente às narrativas hegemônicas e oficiais incorpora exatamente tudo aquilo que é deixado para trás.

Dentro de perspectiva semelhante poderíamos lembrar do geógrafo brasileiro Milton Santos que vai contra o pensamento pretensioso e calcado na visão de história universal, de Francis Fukuyama, de que chegamos ao "fim da história". "Ao contrário do que tanto se disse a história não acabou: ela apenas começa" e este início tem intrínseca relação com o resgate da cidadania e da insurreição dos excluídos, afirma Santos (2000).

Contudo, não foi apenas na arena política que as teses sobre o epílogo coroaram os debates, mas também no campo da filosofia e sociologia. Nos anos 8o, o filósofo francês Jean-François Lyotard (1993) define o pós-moderno como "a incredulidade em relação às metanarrativas”. Com isso ele queria dizer que os grandes esquemas explicativos teriam caído em descrédito e de que não haveria mais garantias para certezas posto que a ciência já não poderia ser considerada como fonte de verdade.

Já Hans Belting chamaria atenção para o fim da história da arte e da própria arte no seu livro O Fim da história da arte: uma revisão dez anos depois, publicado após $O$ fim da história da arte? (1983). 'O fim da arte' não significa que a arte tenha chegado ao fim, mas registra o fato de que na arte, assim como no pensamento da história da arte, delineia-se o fim de uma tradição. 
O que chegou ao fim é uma pretensa história linear da arte que - de 1400 até o final do modernismo, na primeira metade do século XX - foi inteiramente contada sob um ponto de vista euro-ocidental, como se essa fosse uma cultura única e universal.

De um lado, essa pretensa universalidade teria sido desmascarada seja pela existência de culturas que estão muito longe de se identificarem com o modelo euro-ocidental, seja por que o modo tradicional de se narrar a história, por meio de estilos e características precisas linearmente, passou a não dar mais conta dos novos desenvolvimentos artísticos que surgiram depois do fim do modernismo.

No campo da crítica encontramos ideia semelhante: a necessidade de se rever determinados parâmetros 'tradicionais' do juízo estético. Para se compreender as novas manifestações artísticas é necessário, na visão de Arthur Danto (2006), praticar uma nova crítica. Em um mundo marcado pela pluralidade das manifestações artísticas, diferentes princípios devem ser utilizados, sem que da interpretação de uma obra ou de uma série delas se extraia uma definição de 'boa arte' a ser aplicada universalmente.

De fato muitas destas críticas, assim como aquelas empreendidas por Rosalind Krauss (2000) a partir daquilo que ela nomeou de condição pós-midiática, assumiram uma franca oposição em relação à linha hegemônica da crítica de arte representada pela emblemática figura de Clement Greenberg, um dos nomes mais importantes da crítica modernista. Para além da especificidade e de certo purismo das mídias, Rosalind Krauss defende a ideia de um deslocamento de uma visão purista para um olhar que incorpora a hibridação, a contaminação e a relação entre as linguagens.

Acrescente-se a esse breve panorama, a introdução de outras mídias no campo da arte tais como os meios de comunicação - vídeoarte, fax arte, arte postal, arte digital, net- arte, arte móvel, somente para citar alguns exemplos - apontando para uma prática que, para além da 'imobilidade' das linguagens pictóricas e/ou escultóricas tradicionais, incorpora a ideia do tempo e do processo em seu fazer.

E por fim, mas não finalmente, Douglas Crimp em Sobre as ruínas dos Museus (1980) declararia a morte das instituições e mais propriamente dos museus. Nesse ensaio ele se refere à ruína da ficção museológica de representar a arte como um sistema homogêneo, pretensamente universal, e a história da arte como sua classificação ideal. 


\section{História como montagem ou re/escrituras da história}

Acredito que o discurso acerca do fim, seja no campo da história da arte, da arte ou da crítica não deve ser entendido dentro de uma perspectiva apocalíptica, a menos que a palavra "fim" sirva de estímulo para aquilo que entendemos como mudança, como exercício de deslocamento para novas configurações a partir das desterritorializações empreendidas no mundo contemporâneo.

Mais do que atestados de óbito de formas artísticas, vimos surgir uma série de experimentações e discursos que incorporam as demandas colocadas em voga pela contemporaneidade. Agindo sobre novos circuitos, a arte se abre para outros formatos expressivos atuando, muitas vezes, na convergência das linguagens. Para além de seu caráter objetual, incorpora a transitoriedade, a efemeridade, o tempo, a participação, a impermanência, as práticas colaborativas e relacionais em seu fazer.

Neste mar de ruínas talvez fosse interessante resgatar os "cacos" da história, para reconstruir alguns possíveis olhares em relação ao nosso tempo. É na travessia do resgate do passado, na memória, na escuta das vozes que foram soterradas que reside, como diria Walter Benjamin, a possibilidade de realizar o encontro secreto marcado entre as gerações precedentes e a nossa. Benjamin critica a visão modernista da história entendida como continuidade linear, mas nem por isto defende seu fim. Aponta para a necessidade de uma reescritura da história procurando nas descontinuidades momentos críticos quando mudanças podem ocorrer.

O conceito de reescritura para Benjamin surge da necessidade de resistir, de reatar possíveis laços com um passado arruinado pela violência e pela catástrofe. Benjamin propõe, assim, a noção de montagem, tomando-a de empréstimo do cinema e das vanguardas artísticas do início do século passado, como método estratégico para se pensar a escritura historiográfica. Dentro dessa perspectiva, história e mídia se confundem: a história é pensada como mídia, como uma espécie de colagem de tempos e memórias. Assim como o montador edita/corta/interrompe o continuum fílmico, o historiador re/escreve a história: implode o continuum da história da dominação e abre espaço para o tempo do agora. A historiografia para Benjamin deve, portanto, ser redesenhada pelo trabalho da memória: fruto de uma re/escritura que produziria não a imitação/repetição de narrativas anteriores, mas a 'repetição diferente'. 
Paralelamente, percebem-se ao longo do século XIX e XX deslocamentos relacionados à própria historiografia da arte que começa a colocar em debate a visão historicista e de tempo homogêneo, linear e evolutivo, dentro do contexto da história da arte. Aby Warburg, historiador alemão do final do século XIX, com seus estudos sobre o renascimento italiano e florentino, propõe estudos interdisciplinares para a história da arte, relacionando os sistemas simbólicos visuais às tradições culturais locais.

Entre os anos 1923 e 1929, Warburg desenvolve o Atlas Cultural Mnemosyne (Atlas da Memória). O atlas consistiu em um grupo de 63 painéis em que o historiador agrupou perto de mil fotografias relacionadas à história da arte - espécie de arquivo histórico- através das quais mostrava a permanência de certos valores expressivos e imagéticos que sobreviveriam como uma espécie de patrimônio sujeito a leis de transmissão e recepção, na memória coletiva. Para Aby Warburg, a história da arte não é vista sob uma perspectiva linear e evolutiva já que determinadas imagens e gestos retornariam - à semelhança da psicanálise - como espécie de sintomas, dentro do contexto da história da arte.

Reescrever a história da arte, a partir do deslocamento de pontos de vista que incorporem os contextos locais, têm sido uma preocupação constante dos historiadores e críticos de arte no sentido de contribuir para a produção da cultura da diferença e não postular a cultura da repetição, reprodutora de modelos provenientes e originários dos eixos hegemônicos.

\section{$\mathrm{Re}$ /Escrituras da arte: o arquivo e o arquiva- mento como dispositivo para a construção de outras histórias}

Em um momento em que a história e mais precisamente a história da arte tem sido revisitada, nada mais natural que debates sobre como a história da arte é construída - quais são os seus documentos, qual é a sua base documental, que arquivo é este que tem servido de base para sua formação - venham a tona. Não por acaso, as discussões sobre as questões que perpassam o arquivo passam a fazer parte fundamental do contexto contemporâneo, uma vez que a história se escreve com o arquivo, pelo arquivo ou pelo que entendemos como arquivo.

De fato, é impossível negar que o contemporâneo tem sido arrebatado por uma compulsão de pesquisas que giram em torno do arquivo. Vivemos uma febre de arquivo; anseio que abarca desde discussões mais teóricas que colocam em debate o sentido etimológico, filosófico, jurídico e os diferentes sentidos que o ter- 
mo pode ter no resgate da nossa história - seja ela política, social, etnográfica ou cultural - passando, no campo específico da arte, por debates e práticas que se apropriam da temática em questão.

Exposições baseadas integralmente ou parcialmente por questões que perpassam esse conceito, artistas que trabalham com material de arquivo e/ou que discutem metodologias de classificação, arquivologia e museologia, acirradas disputas entre colecionadores privados e museus públicos pela aquisição de obras e arquivos artísticos, até chegar aos debates atuais em torno das políticas de arquivo e acervo institucionais, especialmente aquelas voltadas para o campo da arte contemporânea, são apenas alguns dos exemplos que podemos citar dentro do contexto específico das artes na contemporaneidade.

Para além de entender o arquivo, dentro do contexto atual, como registro dos vestígios e traços deixados da 'obra original' inclusive considerando que o conceito de originalidade na atualidade é bastante problemático - importante é entendê-lo como uma operação intrínseca à parcela da arte contemporânea.

A obra de arte contemporânea é, com efeito, um arquivo em um sentido muito particular: um arquivo - obra aberta a inúmeros desdobramentos, leituras e 'múltiplas narrativas'. Artistas que trabalham com material de arquivo, artistas que criam arquivos fictícios, artistas que problematizam a questão do arquivamento, artistas que desenvolvem projetos a partir de uma modalidade arquival, são algumas das propostas que encontramos no campo da arte contemporânea. Sem pretender esgotar o debate percebe-se, dentro do campo da criação artística contemporânea, alguns vetores e estratégias de trabalho com o arquivo². São eles: reencenação; apropriação; espacialização; in/corporação e metarquivo.

\section{Reencenação: o arquivo como re/encenação}

Dentro de um primeiro vetor é possível destacar projetos que dialogam com a ideia do arquivo como reencenação. Fatos históricos e/ou obras artísticas emblemáticas são pontos de partida para a criação de projetos que, ao 'reencenarem' algo já realizado anteriormente, entendem o 'fato' histórico e a obra de arte como 'documentos-arquivos'; como um processo aberto a múltiplas interpretações e significados. Poderíamos dizer que ao reencenar algo, seja um filme, uma obra de arte ou um evento histórico ganhamos, de alguma forma, a oportunidade de repetir algo diferentemente.

Um dia em que São Paulo Parou desenvolvido pelo artista Lucas Bambozzi para a exposição Re:akt! e depois apresen- 
tada em São Paulo, no Paço das Artes em 2010 na exposição Crossing [Travessias], é um bom exemplo neste sentido.

O interesse pelo impacto da comunicação na percepção e no mundo em que vivemos parece ter sido um dos motivos que impulsionou a criação do projeto que reencena o dia 15 de maio de 2006, quando o Primeiro Comando da Capital (PCC) parou a cidade de São Paulo por meio de articulações realizadas por celulares:

A idéia foi abordar as aparentes contradições de informações veiculadas nos canais preponderantes, antes como flashes, depois como notícias principais - através da formação do grande espetáculo midiático que tomou conta de tudo, quando todo o resto parecia apagado e calado, justamente por conta desse espetáculo. Assim, surgiu um vídeo com mais de 50 canais sobrepostos em linhas de informação (referência às linhas de varredura da TV convencional) sugerindo uma trama fragmentada das diversas imagens e sons sobre o tema. Em um momento posterior, passei a especular sobre a natureza de um evento que foi disparado basicamente através de telefones celulares dentro de cadeias e que, ao mesmo tempo, não possuía nenhum registro de celulares particulares de quem sofreu os atentados. Assim, realizamos uma série de cinco vídeos onde recriamos essa possibilidade de encontrar imagens em cartões de memória de câmeras digitais compactas ou celulares de pessoas comuns que viveram os atentados. Em outro vídeo realizado para a série, experiência do quarto e último momento, utilizamos como base um dos pontos do manifesto do próprio PCC. Pensando em pessoas em vez de organizações, criamos um personagem que teria supostamente ateado fogo em um ônibus, mas cuja ação seria acompanhada de uma crise de consciência - esta relatada a outro integrante que teria registrado casualmente tal confissão (BAMBOZZI apud ARANTES, 2010, p. 89).

O resultado do trabalho é um conjunto fragmentado e multifacetado, um falso documentário, que cria uma relação ambígua entre a realidade e a ficção. De alguma maneira a forma fragmentada do projeto revela a "fragmentação" do próprio fato que foi reencenado no dia, várias vezes através dos canais midiáticos. O projeto neste sentido é um arquivo-obra em duplo sentido. É um arquivo-obra que reencena supostos arquivos perdidos em celulares e/ou cenas de TV, mas, também, arquivo-obra que discute o papel do aparelho midiático como 
dispositivo 'espetacular' de reencenação de um acontecimento.

\section{Apropriação: o arquivo como apropriação}

Dentro de um segundo vetor podemos destacar projetos que se apropriam de imagens e/ou outros dispositivos já existentes, extraídos de arquivos diversos 3 . Neste sentido, muitas vezes, ao se apropriar desses arquivos, o artista desconstrói seu sentido 'original' evidenciando outros sentidos não revelados anteriormente.

Rosângela Rennó trabalha com registros e documentos e faz com que as imagens de arquivo ganhem nova dimensão. Suas fontes de inspiração como jornais, álbuns de família, bibliotecas, 'arquivos mortos' são matérias para a construção de algo vivo.

Em Vulgo, a artista trabalha com material de arquivo pertencente ao Museu Penitenciário de São Paulo. O arquivo, composto por material fotográfico, identifica os prisioneiros por número, características físicas e marcas (como tatuagens e cicatrizes). A artista escolheu doze imagens deste arquivo; todas elas representando redemoinhos do cabelo dos detentos. "Assim como a impressão digital, esses traços físicos são completamente únicos e servem, em sua origem, como identificação dos condenados e reconhecimento de possíveis fugitivos. Em nenhuma das imagens está visível o rosto do fotografado, a maioria focalizando apenas a nuca e o couro cabeludo dos modelos. A intervenção digital da artista se restringe (pelo menos aparentemente) a uma coloração vermelha clara acrescentada justamente no centro do redemoinho do couro cabeludo de cada indivíduo. As imagens resultantes do tratamento digital da artista são, então, ampliadas em grande formato $(165 \mathrm{~cm} \mathrm{X}$ $115 \mathrm{~cm}$ ), ganhando uma dimensão monumental ao serem expostas no espaço expositivo" (VELASCO, 2007).

Ao se apropriar destas imagens Rennó não somente coloca em diálogo a produção artística e o discurso penal, mas também aponta para as estratégias de vigilância e controle da subjetividade exercidas no mundo contemporâneo. Estas imagens, deslocadas de seu lugar original e ampliadas em grande dimensão, são colocadas dentro de um novo contexto discursivo, não somente estético, mas também ético, pois dá visibilidade a procedimentos, muitas vezes questionáveis, implementados pelos dispositivos de poder. Revisitando antigos arquivos, é como se a artista remexesse em um 'cemitério' de imagens dando vida a fantasmas escondidos: oferece, assim, 
novas possibilidades de leitura de uma mesma imagem, negligenciada, muitas vezes, pelo curso da história oficial.

Dentro de outra perspectiva, podemos destacar projetos que se apropriam do 'arquivo' da história da arte, ou melhor, das obras de arte consideradas, aqui, como espécie de 'documentos' da narrativa da história da arte. No vídeo La Liberté Raisonné (A Liberdade Justificada) da artista espanhola Cristina Lucas, atores reencenam a pintura de Eugène Delacroix, Liberdade guiando o povo. Em sua reconstrução, a artista estabelece um final menos feliz para a Liberdade: sua morte faz alusão à crise das utopias e à derrocada daquela desejada vitória da liberdade que, pelo menos historicamente, parece não ter de fato acontecido em meio às mazelas do capitalismo global.

Nestes projetos, os artistas se apropriam de documentos da história e da história da arte. Ao se apropriar destes arquivos, muitas vezes desconstroem e modificam seu sentido 'original', acrescentado-lhes outros significados.

\section{Espacialização: arquivo e monumento no espaço público}

Dentro de um terceiro vetor poderíamos destacar projetos que trazem para o espaço público testemunhos e experiências pessoais. $\mathrm{O}$ que parece interessante nessa estratégia é não somente a diluição das fronteiras entre o público e o privado, mas a utilização de testemunhos para a compreensão e edificação da nossa história.

Para além do monumento tradicional, que geralmente é construído seja para comemorar um acontecimento visto como importante, seja para homenagear uma pessoa ilustre, esses projetos, desenvolvidos no espaço público, podem ser lidos como espécies de 'antimonumentos' que dão voz a pessoas 'comuns'. Trata-se, como diria Walter Benjamin, de escrever, por meio desses projetos, a história a contrapelo, dando espaço a vozes soterradas pela história oficial.

Le Chant dês Sírenes (O Canto das Sereias), do artista Claudio Bueno, é uma espécie de 'antimonumento' sonoro e invisível, instalado no antigo porto de Québec (Canadá). Trata-se de uma homenagem a oito mulheres canadenses que morreram no mar trabalhando com rádio-difusão, nos navios da primeira e segunda guerra mundial. A ideia do projeto foi a de fazer uma espécie de homenagem a essas mulheres através de uma performance sonora realizada na margem do rio Saint-Laurent por cantoras convidadas pelo artista. A performance sonora podia ser ouvida ao nos aproximarmos das margens do rio, com um aplicativo para celular. 


\section{Incorporação: o arquivo no corpo e o corpo como arquivo}

No quarto vetor podemos destacar trabalhos que consideram o corpo como uma espécie de arquivo ou que incorporam o arquivo no próprio tecido corporal. O corpo aqui pode ser entendido como uma espécie de escritura que incorpora marcas, rasuras, indícios significantes de um corpo mensagem em constante processo de construção de sentido.

Dentro dessa perspectiva, podemos lembrar de trabalhos como Marca Registrada, em que Letícia Parente costura Made in Brasil na sola de seu pé; ou projetos como os de Sônia de Andrade, em que a artista corta com uma pequena tesoura os pelos de seu corpo, mutilando sua aparência.

Já em Time Capsule (1997), Eduardo Kac implanta um microchip com um número de identificação em seu tornozelo registrando-se, pela Internet, em um banco de dados. O projeto coloca em debate não somente questões referentes à memória digital, mas, também, dá visibilidade aos processos de vigilância e controle exercidos pela sociedade contemporânea.

\section{Metarquivo e metaobra}

Dentro de uma última perspectiva podemos destacar produções que problematizam questões específicas acerca das metodologias de arquivamento e do colecionismo desenvolvendo uma espécie de metalinguagem. Com seus trabalhos, muitas desses artistas-arquivistas evidenciam as complexidades e ambiguidades inerentes às questões de classificação e armazenamento presentes nas coleções museológicas e institucionais. Desenvolvendo práticas que muitas vezes são atribuídas ao espaço do museu (arquivar, catalogar, classificar, identificar, registrar, reunir, documentar, etc.), esses projetos questionam o arquivo como princípio organizatório fixo e imutável e por isso mesmo dão espaço para pensarmos em outras narrativas e combinações possíveis.

Lidar com coleções já existentes fazendo um museu dentro do museu implica de certa forma, desconstruir o museu e, portanto, certa classificação existente. Concomitante, implica questionar a narrativa museológica predominante no sentido de abrir espaço para outras narrativas possíveis. Ao reconfigurar muitas vezes os arquivos museológicos, o artista-arquivista dá a ver a fragilidade do conceito de arquivo como algo inerte, estimulando, assim, novas leituras interpretativas da própria história da arte 4 . 
O projeto desenvolvido para o Museu da Pampulha pela artista Mabe Bethônico é um bom exemplo neste sentido. No projeto, a artista não partiu das obras da coleção do museu em questão, mas sim do banco de dados que a instituição criou a fim de cadastrar as obras da coleção. Ou seja, não partiu da coleção em si - das obras - mas do banco de dados, do arquivo em texto da coleção formado por formulários - cada qual identificando a peça do acervo - com informações a respeito dos objetos ali inventariados. A partir deste material - dos dados destes formulários - a artista compôs uma nova coleção dentro do museu, evidenciando o fato de que a catalogação já é em si mesma, uma escolha para o desenvolvimento de uma determinada narrativa.

Dentro de perspectiva diversa, mas que diz respeito a projetos que realizam uma espécie de metalinguagem em relação aos processos de arquivamento ou que utilizam o processo de arquivamento como parte integrante da construção da própria obra, podemos lembrar de NBP (Novas Bases para a Personalidade) do artista Ricardo Basbaum.

O projeto NBP, iniciado em 1989, é constituído por diversos projetos e/ou séries. Uma deles chama-se Você gostaria de participar de uma experiência artística?. Nesta série, que teve início em 1994, o artista apresenta uma estrutura de ferro com um buraco no meio e convida diversos participantes a utilizarem este objeto da forma que quiserem. De objeto passivo à forma aberta - ou melhor, a não forma - o objeto torna-se relação, participação, objeto ativo em que os diversos participantes são convidados a usufruir da experiência artística. NBP configura-se, portanto, como uma obra em processo que ativa situações perceptivas e participativas múltiplas.

Os diversos participantes incorporam o objeto no cotidiano vivido, registrando por meio da escrita entre outros dispositivos de registro, as transformações sofridas no processo relacional com o dispositivo. O registro que ocorre durante a fruição do objeto não tem como objetivo, portanto, um lugar no passado, mas uma atualização do sistema. A idéia é não só 'utilizar' a 'forma' como também registrar a experiência através de texto, fotografia, vídeo, som e outros dispositivos. Sendo assim, o registro e seus fluxos deflagratórios, constituem o processo de construção da própria obra: work in progress.

Neste projeto, não somente a obra se desdobra, em suas inúmeras 'réplicas' criativas, mas o processo que se manifesta entre os participantes com a obra - ou seja, as imagens, textos, ações, registros - fazem parte inerente da obra como um sistema sempre em processo, lacunar no seu modus operandi essencialmente arquival. 


\section{Arte contemporânea e arquivo: apontamentos finais}

Dentro deste contexto da produção artística que vai além da arte objetual e de uma arte da presença, os vestígios e os documentos residuais passam, em alguns casos, a fazer parte da operação intrínseca da própria obra, mas não somente. Muitos artistas começam a incorporar em suas obras as discussões que perpassam o arquivo. Artistas que trabalham com material de arquivo, que reencenam obras já conhecidas no contexto da história da arte, artistas que problematizam a questão do arquivamento, artistas que desenvolvem projetos a partir de uma modalidade arquival, são alguns exemplos neste sentido.

Por outro lado, mas não menos importante, entender o arquivo como um processo vivo implica abrir a possibilidade para a compreensão de que sempre é possível a construção de outras e de novos olhares em relação à história e à história da arte.

\section{NOTAS}

1. Muitos dos tópicos abordados neste ensaio são trabalhados em meu livro Re/escrituras da arte contemporânea:história, arquivo e mídia.

2. Importante sinalizar que estes vetores não são estanques, pois muitas vezes misturam-se entre si. Estas divisões são somente um recurso metodológico para facilitar o entendimento da diversidade das produções dentro deste campo.

3. Importante lembrar que o conceito de apropriação nos remete ao texto "Um guia prático para o desvio" de Guy Debord e Gil Wolman, publicado em maio de 1956: "Na verdade é necessário eliminar todos os vestígios da noção de propriedade pessoal nesta área [...]. Quaisquer elementos não importam de onde foram tirados, podem ser usados para fazer novas combinações [...].”.

4. Obviamente, a temática do arquivo ou a utilização de material de arquivo no campo da arte em suas relações com as práticas museais, não é uma prerrogativa presente especificamente no contexto atual. Dentro desta perspectiva poderíamos lembrar de uma série de produções como Boite en valise de Marcel Duchamp, O museu imaginário de André Malraux bem como o Museu fictício de Marcel Broathaers como procedimentos artísticos em que as questões arquivais e documentais já são colocadas em debate.

\section{Referências}

ARANTES, Priscila. Reescrituras da Arte Contemporânea: história, arquivo e mídia. Porto Alegre: Sulina, 2015.

BELTING, Hans. O fim da história da arte: uma revisão dez anos depois. São Paulo:Cosac Naify, 2006.

BENJAMIN, Walter. Magia e Técnica, arte e política. In: Obras 
Escolhidas. Rouanet, P.S. (trad). v.li, 6. ed. São Paulo: Brasiliense, 1993.

CRIMP, Douglas. Sobre as ruínas dos museus. São Paulo, Martins Fontes, 2005.

DANTO, A. Após o fim da arte: a arte contemporânea e os limites da história. São Paulo, Odyssens Editora, 2006.

KRAUSS, Rosalind. A Voyage on the North Sea: art in the age of the post-medium condition. Thames \& Hudson, USA, 2000.

SANTOS, Milton. O recomeço da história. Folha on-line. Disponível em:< http://www1.folha.uol.com.br/fol/brasil5oo/ dc_3_1.htm>. Acesso em: 19 ago.2014.

Recebido em: 10/o6/15

Aceito em: o1/o8/15 


\section{PRISCILA ARANTES}

priscila.a.c.arantes@gmail.com

É pesquisadora, curadora, professora e gestora cultural. É diretora artística e curadora do Paço das Artes, museu da Secretaria de Estado da Cultura de São Paulo, desde 2007. Atualmente é professora do Mestrado e Doutorado em Design na Escola de Artes, Arquitetura e Moda da Universidade Anhembi Morumbi e professora do curso de Arte: história, crítica e curadoria da PUC/SP (Pontifícia Universidade Católica). 